\title{
How is the theoretical domains framework applied to developing health behaviour interventions? A systematic search and narrative synthesis
}

Fiona Cowdell ${ }^{1 *}$ (D) and Judith Dyson ${ }^{2}$

\begin{abstract}
Background: Enabling behaviour change in health care is a complex process. Although the use of theory to inform behaviour change interventions is advocated, there is limited information about how this might best be achieved. There are multiple models of behaviour change, however, due to their complexity they can be inaccessible to both researchers and healthcare practitioners. To support health care practitioner behaviour change, this was addressed by the development of the Theoretical Domains Framework (TDF) in 2005. Citations of the TDF and associated papers have increased exponentially. Although not predicted or intended by the authors, the TDF has also been used to investigate health behaviour change interventions. Therefore our aim was to narratively synthesize empirical evidence on how the TDF and subsequent iterations have been applied in health behaviour change to inform future intervention development.
\end{abstract}

Methods: Systematic search of four online databases, combined with searches for citations of key papers and key author searches, resulted in 3551 articles eligible for screening. Of these 10 met the pre-determined inclusion criteria. Screening of full-texts, data extraction and quality appraisal were independently performed by both authors. Disagreements regarding eligibility were resolved through discussion.

Results: Of the 10 included studies three used the TDF and seven used subsequent iterations, the Capability, Opportunity, Motivation to Behaviour / Behaviour Change Wheel to assess and /or categorise behavioural determinants to identify relevant behaviour change techniques. Two studies reported feasibility testing. Most interventions were targeted at diet and exercise. Eight reported an explicit and systematic process in applying the framework.

Conclusion: There is limited evidence of how the framework has been used to support health behaviour change interventions. In the included studies the process of using the framework is not always reported in detail or with clarity. More recent studies use a systematic and judicious process of framework application. From the limited evidence available we tentatively suggest that the steps proposed in the BCW appear to be sufficient for development of interventions that target health behaviour change interventions. Further research is needed to provide evidence in how the framework may be most effectively applied to intervention development.

Protocol registration: PROSPERO CRD42018086896.

Keywords: Health behaviour change, Theoretical domains framework (TDF), Capability, Opportunity, Motivation to behaviour (COM-B), Behaviour change wheel (BCW), Narrative review

\footnotetext{
* Correspondence: Fiona.cowdell@bcu.ac.uk

${ }^{1}$ Faculty of Health, Education and Life Sciences, Birmingham City University,

Birmingham, UK

Full list of author information is available at the end of the article
}

(c) The Author(s). 2019 Open Access This article is distributed under the terms of the Creative Commons Attribution 4.0 International License (http://creativecommons.org/licenses/by/4.0/), which permits unrestricted use, distribution, and reproduction in any medium, provided you give appropriate credit to the original author(s) and the source, provide a link to the Creative Commons license, and indicate if changes were made. The Creative Commons Public Domain Dedication waiver (http://creativecommons.org/publicdomain/zero/1.0/) applies to the data made available in this article, unless otherwise stated. 


\section{Background}

One important function of health care services is to support and encourage patients or the general population, at individual and community level, to adopt healthy behaviours to reduce the risk of ill-health, maintain health and self-manage long-term conditions [1-3]. However, health behaviour change is a complex process. Although the Medical Research Council guidelines for complex interventions [4] and National Institute for Health and Care Excellence (NICE) recommendations $[1,2]$ advocate the use of theory to inform health behaviour change interventions there is limited information about how this might best be achieved. Systematic reviews of existing evidence demonstrate the effectiveness of such an approach $[5,6]$. The explicit use of theory allows us to understand the mechanisms of change in behaviour and to replicate interventions [7]. There are multiple models of behaviour change that have been used in healthcare (e.g. the Theory of Reasoned Action [8], the Theory Planned Behaviour [9] and the Transtheoretical Model of Behaviour Change [10]). However due to their complexity they can be inaccessible to both researchers and healthcare practitioners.

Michie and colleagues addressed these challenges for the field of implementation science (supporting health care practitioner behaviour change) by using a consensus approach to develop the Theoretical Domains Framework (TDF) [11]. This brings together 33 models of behaviour or behaviour change and includes 128 separate constructs [11]. The TDF has 11 theoretical domains that explain the potential determinants of behaviour (knowledge, skills, social/professional role and identity, beliefs about capabilities, beliefs about consequences, motivation and goals, memory attention and decision processes, environmental context and resources, social influences, emotion and action planning). Subsequent development of the TDF led to validation [12] with 14 domains where optimism, reinforcement and intentions were identified as important and added (rather than being embedded in the earlier 11). Latterly, the Behaviour Change Wheel (BCW) [13] was developed as a "behaviour system", designed to link from identification of determinants of behaviour (using the TDF) to the mapping of appropriate behaviour change techniques (BCTs) to inform interventions.

It consists of "COM-B" (Capability, Opportunity and Motivation to Behaviour) at the hub of the wheel. Use of the COM-B helps identify domains of the TDF most likely to influence behaviour change. In practice, domains of the TDF have been mapped to the COM-B. For example, "Capability" includes the domains knowledge and skills, "Opportunity" incudes social influences and environmental context/resources and "Motivation" includes beliefs about capabilities and emotion [13]. The hub (COM-B) of the BCW is encircled by nine intervention functions (education, persuasion, incentivisation, coercion, training, restriction, environmental restructuring, modelling and enablement) and the outer of the three rings seven policy categories (communication, guidelines, fiscal, regulation, legislation, environmental/ social planning and service provision). The TDF and $\mathrm{BCW}$ (including $\mathrm{COM}-\mathrm{B}$ ) provide a comprehensive eight stage process to intervention design recommended by the authors of the framework: i) define the problem, ii) select the target behaviour, iii) specify the target behaviour and identify iv) what needs to change, v) intervention functions, vi) policy categories, vii) behaviour change techniques (BCTs) and viii) mode of delivery [13].

It is thirteen years since the publication of the TDF and there is limited definitive instruction on how to apply it in intervention design and testing. Michie and colleagues [7] demonstrate how to link behavioural determinants to BCTs. Taylor and colleagues [14] offer a worked example of applying the TDF to healthcare practitioner behaviour. More recently a guide on how to design BCT based interventions has been published [15]. Since 2012 citations of the TDF and associated papers has increased exponentially. Although not predicted or intended by the authors, the TDF and subsequent iterations has also been used to investigate health behaviour change interventions.

The objective of this review was to identify and narratively synthesise papers in which the TDF, or subsequent iterations (hereafter referred to as "the framework"), have been used in relation to health behaviour change interventions with a specific focus on those which report on intervention development and/or testing to inform optimal use in future studies.

\section{Methods}

\section{Search strategies and selection criteria}

The electronic databases Cumulative Index to Nursing and Allied Health Literature (CINAHL), Medline, PsychINFO and Cochrane were searched using the key terms

\section{"theoretical domains framework" or TDF or COM-B or "behav" change wheel" or BCW}

\section{NOT}

Implement" or improv* or quality or guideline ${ }^{*}$ or EBP or "evidence based practice".

Two further searches were conducted using Google Scholar i) citations of key papers [11, 12, 15] and ii) key author searches for papers from Charles Abraham, Lou Atkin, James Cane, Jill Francis, Marie Johnston, Rebecca 
Lawton, and Robert West. The rationale for the latter was that the framework was first cited as the "Theoretical Domains Framework" in 2009 so papers prior to this may not otherwise have been identified and these authors are recognised experts in the field. The search was undertaken in August 2018. Inclusion and exclusion criteria are summarised in Table 1.

Title screening was conducted by a research associate and FC independently. Abstracts were screened for eligibility by JD and FC in accordance with the inclusion and exclusion criteria. Full texts were obtained where there was any doubt about eligibility and authors were contacted in cases of uncertainty. At each stage disagreements were discussed to resolution.

\section{Analysis}

The focus of our review is empirical studies that engaged in intervention design and testing, which we narratively synthesised following the approach of Ferrari [16]. This offers a systematic but straightforward approach appropriate to the nature and homogeneity of the included papers. Data were extracted using a bespoke data extraction table in which we recorded: study design, target group, health behaviour, intervention and framework use. We grouped papers according to the targeted health behaviour. Each paper within the group was discussed and evaluated and application of the framework summarised. Main points were synthesised in relation to our review question and underpin suggestions for future research. Quality of intervention reporting was assessed according to the Template for Intervention Description and Replication (TIDieR) Checklist [17] completed by both authors.

\section{Results}

\section{Search results}

From the original 3551 papers identified 10 met the inclusion criteria. The search process is summarized in Fig. 1 (Preferred Reporting Items for Systematic Reviews and Meta-Analyses: PRISMA flow chart [18]). A summary of included papers is provided in Table 2 and the quality of intervention reporting (design and where applicable delivery and evaluation) is reported in Table 3 [17]. A summary of the key points of the papers is provided followed by a narrative review [16] of papers according to intervention focus.

Included papers were published in 2013 onward and conducted in the UK [19, 22-26, 28], Ireland [21], Australia [27] and the USA [20]. The TDF was used in three papers $[22,26,27]$, and the Com-B/BCW in seven $[19-21,23-25,28]$. The framework was used solely to identify relevant BCTs [20] or to assess and/or to categorise behavioural determinants or barriers and to identify relevant BCTs or to both [19, 21-23, 27, 28]. The eight stage $\mathrm{BCW}$ process was used in three studies [23-25]. In one case a framework based intervention, reported elsewhere [26] was feasibility tested [22].

The majority of interventions were technology based $[19,20,23-25,27,28]$, of these, one included direct contact with a health care provider [20], fewer were face to face delivery only $[21,22,26]$. Interventions targeted children and young people [21] parents [19], overweight pregnant women [22, 26], pregnant smokers [23], smokers [27], sedentary office workers [24], overweight people [25], heterosexual men [28] and people with hypertension [20]. Interventions were designed to target sexual health/contraception [28], smoking [23, 27], diet and exercise $[19,21,22,24-26]$ and specific health condition related behaviours [20]. Each of these categories are addressed in turn below with a specific focus on application of the framework.

\section{Health behaviours targeted Sexual health and contraception}

There was one UK based study that developed an intervention to address sexual health and contraception, this was predominantly male focused [28]. Using the BCW/ Com-B throughout, Webster and colleagues [28] clearly specified the target behaviour and investigated the barriers to condom use through a literature review and interviews with the target population. Interviews also established potential intervention design, content and mode of delivery. Two workshops with experts (one before and one after interviews) involved mapping barriers to explanatory domains, considering intervention functions and design of intervention content. User testing and focus groups refined the ultimate "MenSS" intervention design which was feasibility tested and evaluated.

Table 1 Inclusion and exclusion criteria

\begin{tabular}{ll}
\hline Inclusion & Exclusion \\
\hline Published from 2005 (original publication of the TDF) onwards & \\
Published in English language & $\begin{array}{l}\text { Published in languages other than English (as there } \\
\text { were no resources for translation) } \\
\text { Papers focusing on health behaviour }\end{array}$ \\
$\begin{array}{l}\text { Empirical papers that report design and/ or testing of interventions } \\
\text { underpinned by the TDF or subsequent iterations of the framework }\end{array}$ & \\
\hline
\end{tabular}




\section{WRIS \\ PRISMA 2009 Flow Diagram}

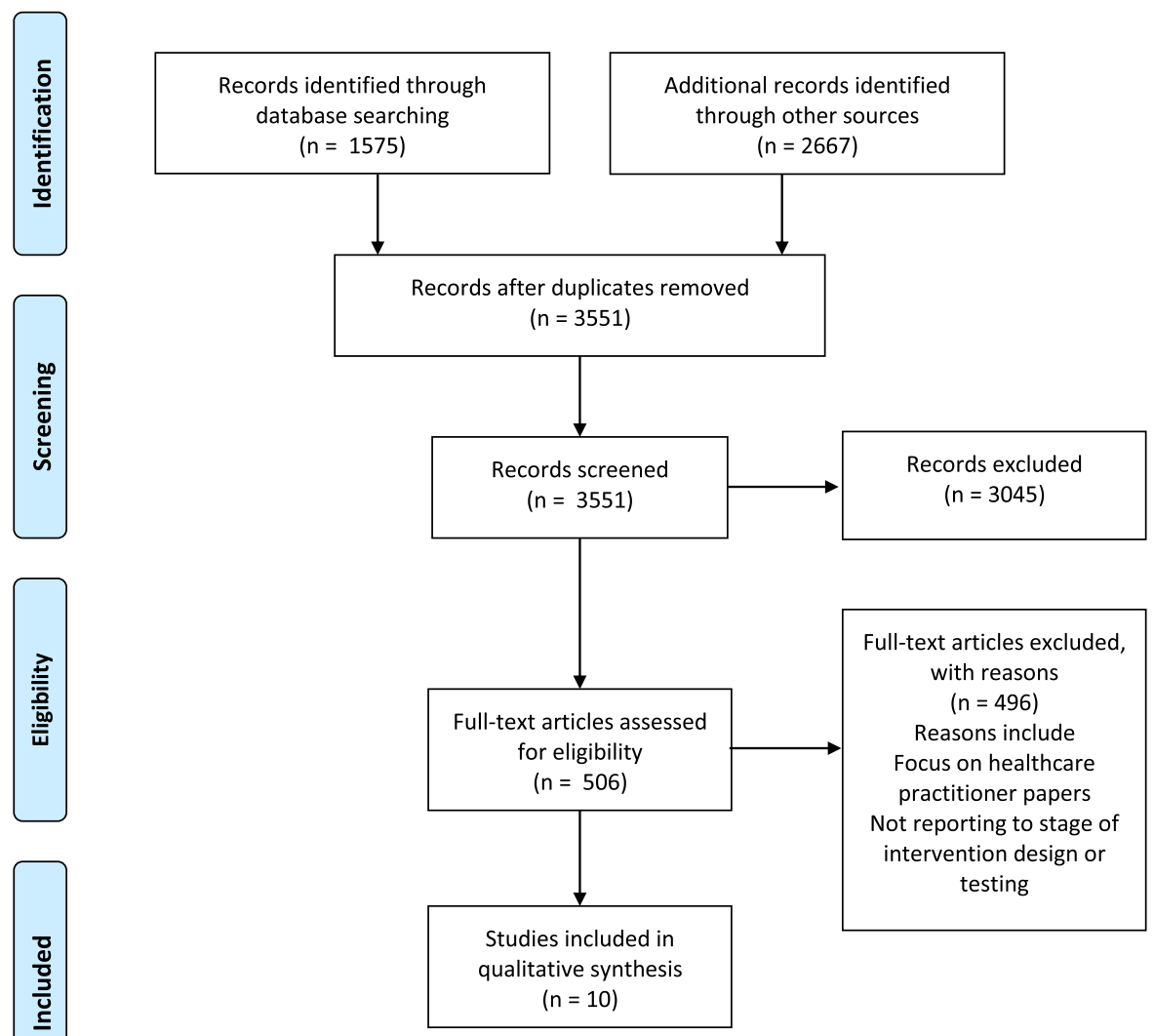

Fig. 1 PRISMA Flow Diagram

\section{Smoking}

There were two studies in this category, one conducted in the UK [23] and one in Australia [27]. Tombor [23] developed "SmokeFree Baby" a smart phone app for pregnant smokers and van Agteren [27] developed the Kick.it mobile health intervention designed to support smoking cessation. Tombor [23] used the TDF to underpin focus groups of healthcare providers and interviews with pregnant smokers to establish what would need to change in pregnant smokers or the environment and conducted a pilot test of the app. Van Agteren [27] used interviews and focus groups, underpinned by the TDF, with smokers and healthcare professionals to assess needs which were mapped to BCTs which and used to inform intervention design.

\section{Diet and exercise}

There were six studies in this category. Five were conducted in the UK $[19,22,24-26]$ and one in Ireland [21]. Two focused on the "HAPPY" intervention $[22,26]$ which was designed for overweight or obese women during and after pregnancy. One focused on children [21], one the parents of children [19], one on overweight people [25] and one sedentary office workers [24]. Two interventions were apps $[19,25]$, one was a monitoring and feedback device [24] and three were designed to be delivered face to face $[21,22,26]$. Taylor and colleagues [26] conducted literature reviews to establish the needs and theoretical determinants to pregnant women adopting a healthy diet and exercise regime. The literature data were supplemented by interviews, focus groups and surveys of parents, grandparents and healthcare professionals. The determinants to diet and exercise behaviours were categorised to the TDF and subsequently mapped to relevant BCTs listed within an existing taxonomy [30]. BCTs underpinned the development of a programme plan. Implementation and evaluation plans were also developed. The intervention itself was subsequently tested by McEachan and colleagues [22] in a feasibility RCT with babies' weight as the primary outcome measure. The intervention 
Table 2 Description of included papers and use of framework $(n=10)$

\begin{tabular}{|c|c|c|c|c|c|}
\hline $\begin{array}{l}\text { First } \\
\text { author, } \\
\text { year (ref) }\end{array}$ & Study design/method & Target group & Health Behaviour & Intervention & Framework use \\
\hline $\begin{array}{l}\text { Curtis, } \\
2015 \text { UK } \\
\text { [19] }\end{array}$ & $\begin{array}{l}\text { BCW framework with user- } \\
\text { centered design informed app } \\
\text { intervention development } \\
\text { process. Existing evidence, } \\
\text { supplemented by thematic } \\
\text { analysis of data from focus } \\
\text { groups }(n=9) \text { with weight } \\
\text { management case workers and } \\
\text { parents of children aged 5-11 } \\
\text { years }(n=46) \text { and experts. }\end{array}$ & Parents & $\begin{array}{l}\text { Provision of } \\
\text { appropriate food } \\
\text { portion sizes }\end{array}$ & $\begin{array}{l}\text { A user-centred healthy eating } \\
\text { app app to target childhood } \\
\text { weight management }\end{array}$ & $\begin{array}{l}\text { COM-B used to assess } \\
\text { determinants through } \\
\text { consideration of current } \\
\text { evidence, focus groups and } \\
\text { consultation with experts. BCW } \\
\text { used to map relevant BCTs }\end{array}$ \\
\hline $\begin{array}{l}\text { Mann, } \\
\text { 2014USA } \\
{[20]}\end{array}$ & $\begin{array}{l}\text { Intervention development by } \\
\text { the research team (no } \\
\text { participants). }\end{array}$ & $\begin{array}{l}\text { People with } \\
\text { hypertension }\end{array}$ & $\begin{array}{l}\text { Lifestyle } \\
\text { including a } \\
\text { healthy diet } \\
\text { (including } \\
\text { reduced sodium } \\
\text { intake) and } \\
\text { exercise }\end{array}$ & $\begin{array}{l}\text { An m-Health version of the } \\
\text { existing DASH (Dietary } \\
\text { Approaches to Stop } \\
\text { Hypertension) intervention. A } \\
\text { hypertension reduction lifestyle } \\
\text { modification system }\end{array}$ & $\begin{array}{l}\text { Implicit use of COM-B to } \\
\text { identify behaviour change } \\
\text { techniques }\end{array}$ \\
\hline $\begin{array}{l}\text { Martin } \\
2015 \\
\text { Ireland [21] }\end{array}$ & $\begin{array}{l}\text { Intervention development and } \\
\text { trial design research team design } \\
\text { no participants. Cluster RCT }\end{array}$ & $\begin{array}{l}\text { Children } \\
8-11 \text { years }\end{array}$ & Exercise & $\begin{array}{l}\text { "Active Classrooms" } 8 \text { week } \\
\text { classroom based physical } \\
\text { intervention aimed to increase } \\
\text { physical activity }\end{array}$ & $\begin{array}{l}\text { Barriers from the literature } \\
\text { categorised to COM-B and } \\
\text { BCW used to identify BCTs }\end{array}$ \\
\hline $\begin{array}{l}\text { McEachan, } \\
\text { 2016 UK } \\
\text { [22] }\end{array}$ & $\begin{array}{l}\text { Feasibility RCT ( } n=120) \text { of an } \\
\text { existing intervention. Consenting } \\
\text { women randomly allocated to } \\
\text { HAPPY or usual care. Outcome } \\
\text { measures for full trial explored. }\end{array}$ & $\begin{array}{l}\text { Overweight } \\
\text { or obese } \\
\text { women } \\
\text { during and } \\
\text { after } \\
\text { pregnancy }\end{array}$ & $\begin{array}{l}\text { Make healthy } \\
\text { food choices and } \\
\text { increase physical } \\
\text { activity }\end{array}$ & $\begin{array}{l}\text { "HAPPY" Healthy and Active } \\
\text { Parenting Programme for early } \\
\text { Years aimed at reducing risk of } \\
\text { obesity in infants of overweight } \\
\text { or obese women. (Details of } \\
\text { intervention in [23]) }\end{array}$ & $\begin{array}{l}\text { Interventions were mapped to } \\
\text { behavioural determinants } \\
\text { which were categorised to the } \\
\text { TDF }\end{array}$ \\
\hline $\begin{array}{l}\text { Munir } \\
2018 \text { UK }\end{array}$ & $\begin{array}{l}\text { Intervention development } \\
\text { involving focus group with NHS }\end{array}$ & $\begin{array}{l}\text { Sedentary } \\
\text { office }\end{array}$ & $\begin{array}{l}\text { Reduction in } \\
\text { time spent sitting }\end{array}$ & $\begin{array}{l}\text { "Stand More AT Work (SMArT } \\
\text { Work)". Four devices that }\end{array}$ & $\begin{array}{l}\text { Intervention design guided by } \\
\text { the BCW eight stage process. }\end{array}$ \\
\hline
\end{tabular}

staff $(n=39)$ to identify barriers and facilitators. Data used with taxonomy of Behaviour Change Techniques to identify strategies for behaviour change. Participant sub-group tested several electronic self-monitoring devices.

Robinson, Intervention development and 2013 UK feasibility testing in 4 week trial [25] involving overweight and obese university staff $(n=12)$. Semistructured interviews to assess acceptability and uncover barriers to use. Adherence monitored electronically

\section{Overweight} people

\section{Attentive eating}

A smartphone based attentive eating intervention to reduce calorie intake
Intervention design guided by BCW eight stage process.
Overweight or obese women during and after of evidence base ii. Desired outcomes and barriers to these identified and mapped in interviews ( $n=12)$, focus groups $(n=27)$ and surveys with parents and grandparents ( $n=$ 1242) and health care practitioners $(n=20)$. Barriers mapped according to psychological determinants. iii.theory based methods for overcoming barriers identified iv. design of intervention $\checkmark$ adoption and implementation in Children Centres
Make healthy food choices and increase physical activity
"HAPPY" Healthy and Active Parenting Programme for early Years to prevent childhood obesity
TDF used to needs assess, identification of barriers, mapping to BCTs. 
Table 2 Description of included papers and use of framework $(n=10)$ (Continued)

\begin{tabular}{|c|c|c|c|c|c|}
\hline $\begin{array}{l}\text { First } \\
\text { author, } \\
\text { year (ref) }\end{array}$ & Study design/method & Target group & Health Behaviour & Intervention & Framework use \\
\hline $\begin{array}{l}\text { Tombor } \\
2016 \text { UK } \\
{[23]}\end{array}$ & $\begin{array}{l}\text { Intervention development in } \\
\text { comprising three main stages } \\
\text { i. preparation, involving focus } \\
\text { groups healthcare providers and } \\
\text { interviews with pregnant } \\
\text { smokers to establish what would } \\
\text { need to change in pregnant } \\
\text { smokers or the environment } \\
\text { ii. design } \\
\text { iii. Piloting with non-pregnant } \\
\text { users }(n=6)\end{array}$ & $\begin{array}{l}\text { Pregnant } \\
\text { smokers }\end{array}$ & $\begin{array}{l}\text { Smoking } \\
\text { cessation }\end{array}$ & $\begin{array}{l}\text { "SmokeFree Baby" smartphone } \\
\text { app to help pregnant women } \\
\text { stop smoking. Includes brief } \\
\text { advice, motivational messages, } \\
\text { positive role models, information } \\
\text { about foetal development and a } \\
\text { video diary. }\end{array}$ & $\begin{array}{l}\text { BCW/COM-B to guide } \\
\text { interviews and focus groups } \\
\text { and to select BCTs. The BCW } \\
\text { eight step process was } \\
\text { followed. }\end{array}$ \\
\hline $\begin{array}{l}\text { van } \\
\text { Agteren } \\
2018 \\
\text { Australia } \\
{[27]}\end{array}$ & $\begin{array}{l}\text { Intervention development using } \\
\text { existing evidence base, } \\
\text { interviews }(n=16) \text { and focus } \\
\text { groups }(n=5) \text { with smokers and } \\
\text { health professionals to assess } \\
\text { needs }\end{array}$ & Smokers & $\begin{array}{l}\text { Smoking } \\
\text { cessation }\end{array}$ & $\begin{array}{l}\text { "Kick.it" a mobile health } \\
\text { intervention involving a logging } \\
\text { smoking and cravings, } \\
\text { reminders, social network, } \\
\text { educational and motivation } \\
\text { videos. }\end{array}$ & $\begin{array}{l}\text { TDF to conduct a needs } \\
\text { assessment mapped to BCTs } \\
\text { which underpinned the } \\
\text { intervention }\end{array}$ \\
\hline $\begin{array}{l}\text { Webster, } \\
2015 \text { UK } \\
{[28]}\end{array}$ & $\begin{array}{l}\text { Intervention development } \\
\text { involved review of existing } \\
\text { evidence, interviews with male } \\
\text { clinic attendants ( } n=20) \\
\text { followed by a workshop of } \\
\text { experts ( } n=13) \text {. Three focus } \\
\text { groups }(n=16) \text { and interviews } \\
(n=7) \text { with clinic users. } \\
\text { Intervention designed to address } \\
\text { target behaviours. User testing } \\
(n=16) \text { to refine intervention. }\end{array}$ & $\begin{array}{l}\text { Heterosexual } \\
\text { men }\end{array}$ & $\begin{array}{l}\text { To increase } \\
\text { condom use }\end{array}$ & $\begin{array}{l}\text { "MenSS" (Men's Safer Sex), an } \\
\text { interactive digital intervention to } \\
\text { prevent sexually transmitted } \\
\text { infections }\end{array}$ & $\begin{array}{l}\text { BCW to categorise behavioural } \\
\text { determinants (from literature, } \\
\text { experts and interviews with } \\
\text { target population) and to } \\
\text { select BCTs }\end{array}$ \\
\hline
\end{tabular}

was evaluated to be acceptable, feasible and demonstrated promising results for infant obesity prevention. The theoretical underpinning of the intervention was not reported or discussed in this paper. Curtis and colleagues [19] used a three stage approach to designing an m-health app targeted at parents to support childhood weight management. A literature review combined with focus groups with stakeholders (case workers and parents) led to selection and definition of the target behaviour, "providing appropriate food portions". COM-B, TDF and existing evidence was used to underpin the focus group question schedule to explore barriers, facilitators and preferences for the final intervention. Barriers categorised to the TDF were mapped to BCTs through use of the BCW. Although the authors report piloting the resulting intervention the results of this are not presented.

Robinson and colleagues [25] reviewed the literature to identify a target behaviour, "eating attentively", as a means of reducing calorie intake and aiding weight loss. They used the COM-B to list strengths of smartphone technology. The authors report the app content but make no further reference to the framework. Feasibility testing with obese adults was conducted. Primary outcome measures were i) frequency of use, ii) qualitative evaluation of the effects of using the app' and factors affecting use and iii) self-reported acceptance. Whilst not a primary outcome measure weight changes were monitored. The intervention evaluation demonstrated equivocal results on all measures. Munir et al. [24] comprehensively applied the eight stages of the BCW. Martin and Murtagh [21] described intervention design and present a protocol for a cluster RCT to test a classroom based 8 week intervention to increase activity. A literature review was used to identify barriers and facilitators to integrating physical movement into classroom activities. These were categorised to the COM-B and the $\mathrm{BCW}$ used to identify appropriate BCTs.

\section{Specific behaviours for specific groups}

One study was included in this category, a US based, mhealth intervention addressing dietary approaches to the management of hypertension [20]. Mann and colleagues [20] considered diet and exercise focusing on specific blood-pressure related elements (e.g. salt intake) and therefore we have categorised it as an intervention for a specific health condition. These authors adapted the mode of delivery of the effective and established "DASH" (Dietary Approaches to Stop Hypertension) intervention from face to face and web-based to mobile app. Mann and colleagues [20] cite the COM-B/BCW and appear to 


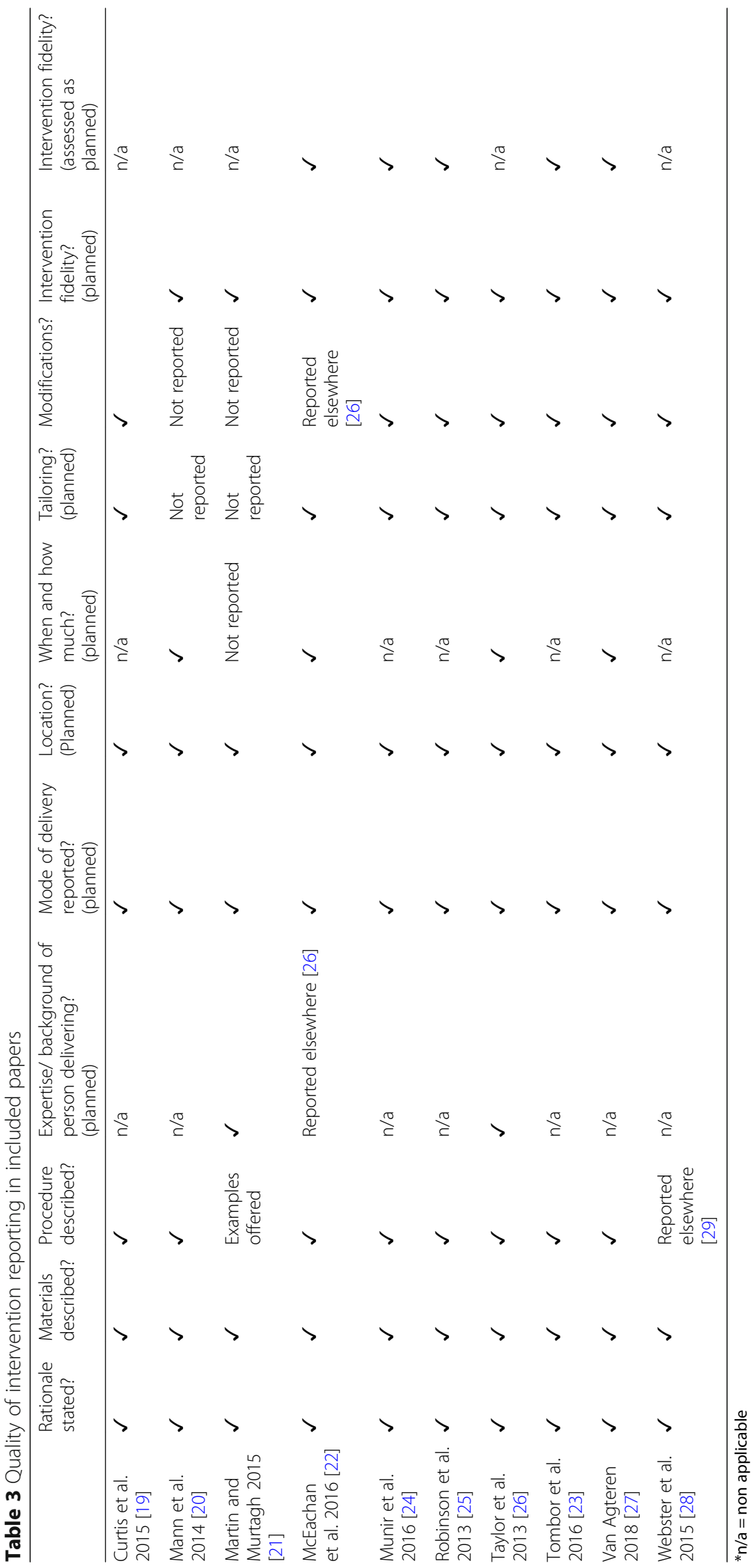


include three BCTs; educational clips, coaching and motivational interviewing. There is no further description of the use of theory in the development of the M-health "DASH" intervention.

Above we have presented our findings with regard to our review question "How is the Theoretical Domains Framework applied in health behaviour change interventions?". Although there is no established "gold standard" here we critique the process of applying the framework in the light of published guidance and examples [4, 5, 31, 32]. Eight of the included papers reported an explicit and systematic process in applying the framework to intervention design and testing [19, 21-24, 26-28].

All defined the target health behaviour and gave a clear account of relevant behavioural determinants which were established through a range of techniques. Although the use of theory in intervention design was thoroughly reported by Curtis et al., the description of the process was relatively complex to follow. Two papers $[20,25]$ were less explicit in their application of the framework. Robinson and colleagues [25] "assume(d)"the barriers and facilitators to eating attentively rather than systematically investigating these. Although the authors state they used the BCW to understand the behavioural determinants to the target behaviour in fact they appear to have used it to understand the determinants to intervention uptake. Whilst the electronic process of the $\mathrm{m}$ health DASH intervention is explicit and detailed, Mann and colleagues [20] make limited reference to the contribution of behaviour change theory. The most recent three papers offer the clearest and most detailed explanation of application of the framework to intervention design [23, 24, 27].

\section{Discussion}

The aim of our review was to establish how the TDF and subsequent iterations of the framework have been applied in health behaviour change interventions. Following a rigorous selection process, 10 papers met our inclusion criteria. All ten reported intervention development and two of these went on to test the feasibility of the intervention. The TDF was used in three papers and the $\mathrm{COM}-\mathrm{B} / \mathrm{BCW}$ in seven. Seven interventions were predominantly technology based and three were face to face. Interventions were categorised according to target health behaviours which were sexual health/contraception, smoking cessation, diet and exercise and specific behaviours for specific groups.

Critique of the framework in the included papers suggested that it was time consuming to apply (particularly where there are multiple target behaviours) [28] and requiring intervention developers to have a knowledge of both the process and relevant BCTs [28]. Webster and colleagues [28] report the framework enables a clear process of design and makes explicit active ingredients (BCTs) which allows intervention replication.

There are two other reviews that have considered the use of the TDF. A synthesis of the use of the TDF in 2012 identified 133 papers which cite the framework, 21 of these were empirical studies and of these only four investigated the health behaviour change interventions [33]. Only one of these papers involved intervention design and is therefore also included in our review. Birken et al. 2017 [34] sought to elicit the rational of authors in combining the Consolidated Framework for Implementation Research (CFIR) and the TDF. All of their 12 included papers focused on practitioner rather than patient and general public health behaviours. There is one review protocol [35] considering how the framework is applied in designing interventions to support healthcare practitioner behaviour change.

Although we were systematic in our search, it is possible that we have not identified papers published before common use of the name "Theoretical Domains Framework (TDF)" which appears to have first been documented in 2009 [36]. Whilst we acknowledge that the TDF was designed to support healthcare practitioner behaviours it has also been extensively cited in the health behaviour change literature thus justifying this review. This number of citations may be due to the lack of an alternative framework. The only comparator we are aware of is Fishbein's approach [8] which was developed with specific regard to people with Human Immunodeficiency Virus. However despite many citations in empirical papers only twelve use the TDF and subsequent iterations for intervention design and testing.

\section{Conclusion}

There is limited evidence of how the framework has been used to support health behaviour change interventions. In the included studies the process of using the framework is not always reported in detail or with clarity. The more recent studies use a systematic and judicious process of framework application. Due to small numbers and unclear reporting of the use of the framework in two of the included papers is not possible to comment on any association between the use of robust methods for intervention development and feasibility or effectiveness of the resulting intervention; this is worthy of consideration in future reviews. From the limited evidence available we tentatively suggest that the steps proposed in the BCW appear to be sufficient for development of interventions that target health behaviour change interventions. Further research is needed to provide evidence in how the framework may be most effectively applied to intervention development. 


\section{Abbreviations}

BCTs: behaviour change techniques; BCW: Behaviour Change Wheel; COM-B: Capability, Opportunity, Motivation to Behaviour; NICE: National Institute for Health and Care Excellence; TDF: Theoretical Domains Framework; TIDieR: Template for Intervention Description and Replication

\section{Acknowledgements}

We extend our thanks for Dr. Carol Lambert, University of Hull for her help in the early stages of developing this review and to Dr. Lisa Marie Thompson for her review of an earlier iteration of this paper.

\section{Authors' contributions}

FC and JD have been equal contributors in the production of this manuscript. Both authors read and approved the final manuscript.

\section{Fundings}

This report is independent research arising from a Knowledge Mobilisation Research Fellowship, Professor Fiona Cowdell, KMRF-2015-04-004 supported by the National Institute for Health Research. The views expressed in this publication are those of the authors and not necessarily those of the NHS, the National Institute for Health Research, Health Education England or the Department of Health.

The National Institute for Health Research played no part in design, analysis or interpretation in this review.

\section{Availability of data and materials}

Not applicable

\section{Ethics approval and consent to participate}

Not applicable

\section{Consent for publication}

Not applicable

\section{Competing interests}

The authors declare that they have no competing interests.

\section{Author details}

${ }^{1}$ Faculty of Health, Education and Life Sciences, Birmingham City University, Birmingham, UK. ${ }^{2}$ Faculty of Health Sciences, University of Hull, Hull, UK.

\section{Received: 13 August 2018 Accepted: 5 August 2019}

Published online: 28 August 2019

\section{References}

1. National Institute for Health and Care Excellence, Behaviur Change: General approaches Public health guideline [PH6] 2007 [Available from: https:// www.nice.org.uk/Guidance/PH6 Accessed 13 Aug 2018.

2. National Institute for Health and Care Excellence, Behaviour change: individual approaches Public health guideline [PH49] 2014 [Available from: https://www.nice.org.uk/Guidance/PH49 Accessed 13 Aug 2018.

3. Free C, Phillips G, Galli L, Watson L, Felix L, Edwards P, et al. The effectiveness of mobile-health technology-based health behaviour change or disease management interventions for health care consumers: a systematic review. PLoS Med. 2013:10(1):e1001362.

4. Craig P, Dieppe P, Macintyre S, Michie S, Nazareth I, Petticrew M. Developing and evaluating complex interventions: the new Medical Research Council guidance. Bmj. 2008;337:a1655.

5. Taylor N, Conner M, Lawton R. The impact of theory on the effectiveness of worksite physical activity interventions: a meta-analysis and meta-regression. Health Psychol Rev. 2012;6(1):33-73.

6. Webb TL, Joseph J, Yardley L, Michie S. Using the internet to promote health behavior change: a systematic review and meta-analysis of the impact of theoretical basis, use of behavior change techniques, and mode of delivery on efficacy. J Med Internet Res. 2010;12(1):e4.

7. Michie S, Hardeman W, Fanshawe T, Prevost AT, Taylor L, Kinmonth AL. Investigating theoretical explanations for behaviour change: the case study of ProActive. Psychol Health. 2008:23(1):25-39.

8. Fishbein M. The role of theory in HIV prevention. AIDS Care. 2000;12(3):273-8

9. Ajzen I. The theory of planned behavior. Organ Behav Hum Decis Process. 1991;50(2):179-211.
10. Prochaska JO, DiClemente CC. Transtheoretical therapy: toward a more integrative model of change. Psychol Psychother Theory Res Pract. 1982;19(3):276.

11. Michie S, Johnston M, Abraham C, Lawton R, Parker D, Walker A. Making psychological theory useful for implementing evidence based practice: a consensus approach. BMJ Quality \& Safety. 2005;14(1):26-33.

12. Cane J, O'Connor D, Michie S. Validation of the theoretical domains framework for use in behaviour change and implementation research. Implement Sci. 2012;7(1):37.

13. Michie S, Atkins L, West R. The behavior change wheel: a guide to designing interventions. Great Britain: Silverback Publishing; 2014.

14. Taylor N, Lawton R, Slater B, Foy R. The demonstration of a theory-based approach to the design of localized patient safety interventions. Implement Sci. 2013:8(1):123.

15. Michie S, Van Stralen MM, West R. The behaviour change wheel: a new method for characterising and designing behaviour change interventions. Implement Sci. 2011;6(1):42.

16. Ferrari R. Writing narrative style literature reviews. Medical Writing. 2015; 24(4):230-5

17. Hoffmann TC, Glasziou PP, Boutron I, Milne R, Perera R, Moher D, et al, Better reporting of interventions: template for intervention description and replication (TIDieR) checklist and guide. Bmj. 2014;348:g1687.

18. Moher D, Liberati A, Tetzlaff J, Altman DG. Preferred reporting items for systematic reviews and meta-analyses: the PRISMA statement. Ann Intern Med. 2009;151(4):264-9.

19. Curtis KE, Lahiri S, Brown KE. Targeting parents for childhood weight management: development of a theory-driven and user-centered healthy eating app. JMIR Mhealth Uhealth. 2015;3(2):e69.

20. Mann DM, Quintiliani LM, Reddy S, Kitos NR, Weng M. Dietary approaches to stop hypertension: lessons learned from a case study on the development of an mhealth behavior change system. JMIR Mhealth Uhealth. 2014;2(4):e41.

21. Martin R, Murtagh EM. An intervention to improve the physical activity levels of children: design and rationale of the 'active classrooms' cluster randomised controlled trial. Contemp Clin Trials. 2015:41:180-91.

22. McEachan RR, Santorelli G, Bryant M, Sahota P, Farrar D, Small N, et al. The HAPPY (healthy and active parenting Programmme for early years) feasibility randomised control trial: acceptability and feasibility of an intervention to reduce infant obesity. BMC Public Health. 2016;16(1):211.

23. Tombor I, Shahab L, Brown J, Crane D, Michie S, West R. Development of SmokeFree baby: a smoking cessation smartphone app for pregnant smokers. Transl Behav Med. 2016;6(4):533-45.

24. Munir F, Biddle SJ, Davies MJ, Dunstan D, Esliger D, Gray LJ, et al. Stand more AT work (SMArT work): using the behaviour change wheel to develop an intervention to reduce sitting time in the workplace. BMC Public Health. 2018:18(1):319.

25. Robinson E, Higgs S, Daley AJ, Jolly K, Lycett D, Lewis A, et al. Development and feasibility testing of a smart phone based attentive eating intervention. BMC Public Health. 2013;13(1):639.

26. Taylor NJ, Sahota P, Sargent J, Barber S, Loach J, Louch G, et al. Using intervention mapping to develop a culturally appropriate intervention to prevent childhood obesity: the HAPPY (healthy and active parenting Programme for early years) study. Int J Behav Nutr Phys Act. 2013;10(1):142.

27. van Agteren JE, Lawn S, Bonevski B, Smith BJ. Kick. It: the development of an evidence-based smoking cessation smartphone app. Transl Behav Med. 2018;8(2):243-67.

28. Webster R, Michie S, Estcourt C, Gerressu M, Bailey J, Group MT. Increasing condom use in heterosexual men: development of a theory-based interactive digital intervention. Transl Behav Med. 2015;6(3):418-27.

29. Webster R, Gerressu M, Michie S, Estcourt C, Anderson J, Ang CS, et al. Defining the content of an online sexual health intervention: the MenSS website. JMIR Res Protoc. 2015;4(3):e82.

30. Abraham C, Michie S. A taxonomy of behavior change techniques used in interventions. Health Psychol. 2008;27(3):379.

31. Cadogan CA, Ryan C, Francis JJ, Gormley GJ, Passmore P, Kerse N, et al. Development of an intervention to improve appropriate polypharmacy in older people in primary care using a theory-based method. BMC Health Serv Res. 2016;16(1):661

32. French SD, McKenzie JE, O'Connor DA Grimshaw JM, Mortimer D, Francis tلر et al. Evaluation of a theory-informed implementation intervention for the management of acute low back pain in general medical practice: the IMPLEMENT cluster randomised trial. PLoS One. 2013;8(6):e65471. 
33. Francis JJ, O'Connor D, Curran J. Theories of behaviour change synthesised into a set of theoretical groupings: introducing a thematic series on the theoretical domains framework. Implement Sci. 2012;7(1):35.

34. Birken SA, Powell BJ, Presseau J, Kirk MA, Lorencatto F, Gould NJ, et al.

Combined use of the consolidated framework for implementation research (CFIR) and the theoretical domains framework (TDF): a systematic review. Implement Sci. 2017;12(1):2.

35. Dyson J, Cowdell F, Aspland J. How is the Theoretical Domains Framework applied in designing interventions to support healthcare practitioner behaviour change? A systematic search and narrative synthesis. PROSPERO. 2017;CRD 42018087233. https://www.crd.york.ac.uk/PROSPERO/display_ record.php?RecordID=86896

36. Francis JJ, Stockton C, Eccles MP, Johnston M, Cuthbertson BH, Grimshaw $\mathrm{JM}$, et al. Evidence-based selection of theories for designing behaviour change interventions: using methods based on theoretical construct domains to understand clinicians' blood transfusion behaviour. Br J Health Psychol. 2009;14(4):625-46.

\section{Publisher's Note}

Springer Nature remains neutral with regard to jurisdictional claims in published maps and institutional affiliations.

Ready to submit your research? Choose BMC and benefit from:

- fast, convenient online submission

- thorough peer review by experienced researchers in your field

- rapid publication on acceptance

- support for research data, including large and complex data types

- gold Open Access which fosters wider collaboration and increased citations

- maximum visibility for your research: over $100 \mathrm{M}$ website views per year

At BMC, research is always in progress.

Learn more biomedcentral.com/submissions 